\title{
Descriptive study on pre-anae sthetic information desired by patients who undergo surgery
}

\author{
Wellala K.W.M ${ }^{1}$, Nanayakkara A.I ${ }^{1}$, De Silva $A^{2}$, Ponnamperuma ${ }^{3}$ \\ Medical student ${ }^{1,}$ Senior Lecturer ${ }^{2,}$ Faculty of Medicine, University of Ruhuna
}

*Corresponding author: manidu4me@yahoo.com

Keywords: pre-anaesthetic information, pre-anaesthetic visit,

\begin{abstract}
Introduction:
Delivery of pre-anaesthetic information is ethical, professional and a legal requirement in patient care. It is important for anaesthetists to know about pre-anaesthetic information the patient desire.
\end{abstract}

\begin{abstract}
Methods:
This descriptive cross-sectional study was conducted on 200 preoperative patients covering all surgical units $(\mathrm{n}=9)$ at Teaching Hospital, Karapitiya. Data was collected using an interviewer administered questionnaire to describe the pre-anaesthetic information desired by the patient, differences between desire for information according to the types of surgery and anaesthetic methods, and to determine associations between desire for information according to age, gender, educational status and economical status.

Results:

149 patients and 51 guardians ranging from 14-79 years in age (Mean 43.95 years) participated in this study. There were $58.5 \%$ males and $42.5 \%$ females. Majority of them had studied up to advanced level, and nearly $75 \%$ had a monthly income which is less than Rs.20,000. More than half of the consent providers wanted to meet the anaesthetist before the surgery and more than two thirds of them said that they have an absolute desire for more information regarding the forthcoming anaesthesia. Only one third of them desired anaesthetic drug information. Desire for pre-anaesthetic information was statistically associated with age $(\mathrm{p}=0.000)$ and gender, but it showed no association with economical status, type of surgery or type of anaesthesia.
\end{abstract}

\section{Conclusion \& recommendation:}

Majority of the study sample wished to get anaesthetic information $(72.5 \%)$ and to meet the anaesthetist preoperatively (54.5\%). Delivering pre-anaesthetic information irrespective of type of surgery and type of anaesthesia including the information desired by the patients will improve the patient satisfaction.

Anaesthesia is associated with its own particular risks and consequences quite apart from those associated with the surgical procedure ${ }^{1}$. Therefore obtaining the informed consent not only for the surgery but also for the anaesthesia is necessary ${ }^{1}$.

The legal requirement of informed consent requires that the anaesthetist provides the patients with necessary information and understanding to conduct an anaesthetic procedure ${ }^{1}$.Obtaining consent for anaesthesia can be considered as valid only if adequate information is supplied and understood $^{2}$. Anaesthetists should record details of the elements of the discussion in the patient record, noting the risks, benefits and alternatives which were explained to the patient ${ }^{3}$. Furthermore communication between the anaesthetist and the patient is being considered as an increasingly important aspect of clinical care ${ }^{4,5}$.

The importance of providing pre-anaesthetic information to reduce the anxiety of patient was highlighted in a study, in which it was found that pre-operative delivery of information using multimedia reduces the anxiety of patients who undergo surgery under regional anaesthesia ${ }^{6}$. 
Another study revealed that providing of highly detailed anaesthetic risk information prior to paediatric surgery does not increase parental anxiety level ${ }^{7}$. Taking all these things into account, anaesthetic departments of western countries now practice supplying written information about anaesthesia to their patients and obtaining separate informed consent for anaesthesia, ${ }^{3,8}$. Unfortunately in Sri Lanka, the current practice still neglects these aspects.

The desire for anaesthetic information may depend on personal factors and surgical and anaesthetic procedures they undergo. Studies related to patients' expectations and desires about anaesthesia seems to be very limited in Sri Lanka. In this study, the investigators aimed to investigate the information that patients wish to receive and to determine their association with the personal factors such as age, gender, educational status, economical status, type of surgery and type of anaesthesia.

\section{Method}

This descriptive cross sectional study was carried out at Teaching Hospital Karapitiya (THK). All patients who underwent all types of surgeries in all surgical wards at THK were recruited for this study. They underwent either general or regional anaesthesia. Consent providers didn't refuse to give the consent to participate in the study.

Collection of data was done using an interviewer administered questionnaire which was prepared by the investigators themselves. The questionnaire contained;

1. Basic demographic data of the person who gave the consent for the surgery.

(age, gender, socio-economic status, educational status)

2. Surgical and anaesthetic information.

The type of surgery was categorised as Major Routine, Major Urgent, Minor Routine and Minor Urgent procedures. All the surgeries which opened the abdominal cavity, thoracic cavity, skull or dural sheets and surgeries with a high tendency to massive bleeding were considered as major surgeries and the remaining were considered as minor surgeries. Planned and elective surgeries were categorised as routine surgeries and emergency surgeries in casualty theatres were categorised as urgent surgeries.

The method of anaesthesia was categorised as regional and general anaesthesia.

3. Pre-anaesthetic information desired by the person who gave the consent for a surgery.

This section consisted of ten questions and the answers were assessed using 'Five Point Likert Scale'. The first question assessed whether they desire to meet the anaesthetist prior to the surgery. The next eight questions assessed whether they have the desire for preanaesthetic information and the answers were given marks ranging from $0-4$. The total rating range from 0-32 was taken in to analysis and when desire for pre-anaesthetic information was assessed the score was categorised into three as in "Do not desire pre-anaesthetic information" score 0-8, "Inconclusive" 9-16 and "Definite desire for pre anaesthetic information" 17-32. The last question assessed whether they need any other information regarding anaesthesia. The questionnaire was tested prior to the proper study.

Data was collected by investigators themselves on 200 subjects within four consecutive days of the last week of September 2010. Information was taken prior to their surgeries and data was collected directly from the patient or the guardian of paediatric and critically ill patients.

Ethical clearance for this study was obtained from the Institutional Ethical Review Board, Faculty of Medicine, University of Ruhuna, Galle, Sri Lanka. Informed written consent was obtained from the patient or the guardian of the patient.

The data analysis was done using SPSS software (version 17). The sample was described using descriptive statistics.

\section{Results}

The response rate was $100 \%$. There were 149 patients who gave consent for their own surgery and 51 guardians who gave consent on behalf of patients undergoing surgery. Among the guardians, 49 were parents of paediatric patients and 2 were relatives of critically ill patients. The age of the patients who underwent surgery ranged from 3 weeks to 79 years. The age of the person 
who gave the consent for the surgery ranged from 14 to 79 years with a mean age of 43.95 .

Further analyses and description of data were with regard to the person who gave the consent for the surgery. There were 117 males and 83 females in the study. Some of them have never been to school and some have had higher education, where $42.5 \%$ of them had studied up to advanced level in the Sri Lankan education system (table 1).

Table 1 Educational Status of the subjects



The socioeconomic status was fairly low in the participants where nearly $75 \%$ of them had an income less than 20,000 Rupees per month (table 2).

Table 2 Socio-economic status of the subjects according to the monthly income

\begin{tabular}{|c|c|c|c|c|c|}
\hline \multirow[t]{4}{*}{ Valid } & $<R s 10000$ & $\begin{array}{l}\text { Frequency } \\
64\end{array}$ & $\begin{array}{l}\text { Percent } \\
32.0\end{array}$ & $\begin{array}{l}\text { Valid } \\
\text { Percent } \\
32.0\end{array}$ & $\begin{array}{l}\text { Cumulative } \\
\text { Percent } \\
32.0\end{array}$ \\
\hline & Rs $10001-20000$ & 85 & 42.5 & 42.5 & 74.5 \\
\hline & Rs $20001-30000$ & 39 & 19.5 & 19.5 & 94.0 \\
\hline & $>$ Rs 30000 & 12 & 6.0 & 6.0 & 100.0 \\
\hline
\end{tabular}

The surgeries were carried out in the general surgical, orthopaedic, maxillofacial, ear-nosethroat (ENT), genitor-urinary, cardio-thoracic, neurosurgical, ophthalmology and paediatric surgical units of THK, where half of the surgeries were carried out in the general surgical units.

Surgeries were categorised into four groups and majority (54\%) underwent minor routine surgeries and only $5 \%$ underwent major urgent surgeries.

The number of surgeries done under general anaesthesia were $155(77.5 \%)$ while the remaining $45(22.5 \%)$ were done under regional anaesthesia.

The anaesthetic information requested was on different parameters, $87 \%$ of the study sample desired to know the measures that can be taken to minimize the side effects due to anaesthetic procedures while $71.5 \%$ desired to know the side effects due to anaesthetic procedures. $74.5 \%$ desired to obtain information on the importance of fasting prior to the surgery and $74 \%$ desired to know about the type of anaesthesia planned for them while $54.5 \%$ were interested in other types of anaesthesia available. The duration planned for anaesthetic procedure was requested by $70 \%$ and $70.5 \%$ desired knowledge about the post-operative feeling. Only $34.5 \%$ were interested in information regarding drugs used in anaesthetic procedure. (Chart 1)

Chart 1 Percentage of information desire Different parameters of pre-anaesthetic information.

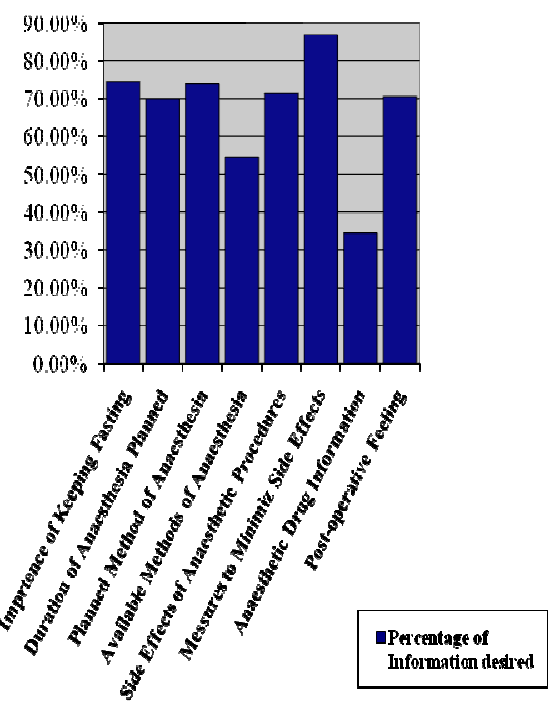

Pre-anaesthetic information was definitely requested by $145(72.5 \%)$ while $7(3.5 \%)$ of the study sample did not want pre-anaesthetic information and 48 (24\%) were inconclusive. Compared to males $(65.5 \%)$ majority of the females needed more information $(81.93 \%)$ and the difference is statistically significant $(\mathrm{p}<0.000)$. Age of the patients was negatively related to desire for anaesthetic information $(r=-0.196, p<.05)$ where younger patients were requesting more information. According to the chi square statistics, there is no significant association between the 
desire for pre-anaesthetic information and the socioeconomic status.

According to the type of surgery, more than $60 \%$ of the people of the sample who underwent all types of surgeries said that they definitely have a desire for pre-anaesthetic information.

Regarding type of anaesthesia $76.6 \%(n=111)$ of patients who underwent general anaesthesia and $61.8 \%(n=34 \%)$ of the patients who underwent regional anaesthesia desired pre-anaesthetic information (table 3).

Table 3 Method of anaesthesia total pre-anaesthetic information category

\begin{tabular}{|c|c|c|c|c|c|c|}
\hline \multirow{3}{*}{$\begin{array}{l}\text { Method } \\
\text { of } \\
\text { anaesthesia }\end{array}$} & GA & Count & \multicolumn{3}{|c|}{$\begin{array}{l}\text { Total pre-anaesthetic information } \\
\text { category } \\
\text { No }\end{array}$} & $\begin{array}{l}\text { Total } \\
145\end{array}$ \\
\hline & & $\begin{array}{l}\% \text { within } \\
\text { method of } \\
\text { anaesthesia }\end{array}$ & $3.4 \%$ & $20.0 \%$ & $76.6 \%$ & $100.0 \%$ \\
\hline & RA & $\begin{array}{l}\text { Count } \\
\% \text { within } \\
\text { method of } \\
\text { anaesthesia }\end{array}$ & $\begin{array}{l}2 \\
3.6 \%\end{array}$ & $\begin{array}{l}19 \\
34.5 \%\end{array}$ & $\begin{array}{l}34 \\
61.8 \%\end{array}$ & $\begin{array}{l}55 \\
100.0 \%\end{array}$ \\
\hline
\end{tabular}

According to the "T test" findings with reference to the total desire for anaesthetic information, the difference between the mean scores of the two groups of major surgeries and minor surgeries were not statistically significant $(\mathrm{p}=0.713)$. The difference between the mean scores of routing and urgent surgeries were also not statistically significant $(\mathrm{p}=0.665)$. The difference between the mean scores of the two groups of general anaesthesia and regional anaesthesia were also not statistically significant $(\mathrm{p}=0.120)$.

From the subjects, $54.5 \%(\mathrm{n}=109)$ said that they have a distinct desire to meet the anaesthetist prior to the surgery while $37.5 \%(n=75)$ said that they do not desire to meet the anaesthetist, and $8 \%$ $(n=16)$ had no idea about it. More than two thirds of females $(65.06 \%)$ desired to meet the anaesthetist. People who were educated up to and above ordinary level at school had more interest in meeting the anaesthetist $(62.39 \%)$ when compared to people who were educated below ordinary level at school $(37.61 \%)$.
Meeting the anaesthetist prior to the surgery has a significant statistical association $(<0.05)$ with gender, educational status and type of surgery according to the chi square test findings.

\section{Discussion}

This study highlighted the fact that majority of the patients have a definite desire for pre-anaesthetic information. Females were more interested in gaining information when compared to males in this study, which is also highlighted in Jamaican ${ }^{9}$ and Canadian ${ }^{10}$ studies regarding the desire for anaesthetic information. These findings conflict with the findings of an Italian study where they had found that there is no association between gender and desire for pre-anaesthetic information 11. In our study, we found that patients below 30 years of age $(81.25 \%)$ were keener on getting more information which is compatible with the findings of an Australian study where they said patients under the age of 50 years had a greater desire for information than those who were older 12 .

Irrespective of the economic status and the educational level, patients wish to receive preanaesthetic information. Desire for information had no significant association with the type of surgery or method of anaesthesia planned. In this study we have found out that attention of the patient or the guardian is mainly focused on side effects of anaesthetic procedure and the measures that can be taken to minimise them. Information regarding reasons to keep fasting prior to the surgery, duration of anaesthesia, post-anaesthetic feeling, available anaesthetic options and the planned anaesthetic procedure to the patient were requested by more than two thirds of the study sample. Nearly a third of the study sample desired information regarding anaesthetic drugs. This finding is compatible with the findings of a randomised control trial conducted in United Kingdom regarding detailed anaesthetic drug information before anaesthesia ${ }^{13}$.

The majority (54.5\%) of the study sample wishes to communicate with their anaesthetist prior to the surgery which is not significantly prioritised as the studies in Australia ${ }^{12}$, Canada and Scotland ${ }^{10}$. The number of consent providers who wish to communicate with the anaesthetist $(n=109)$ is not 
as high as the number who desire pre-anaesthetic information $(n=149)$. This implies that there is a group of consent providers who definitely desire pre-anaesthetic information but find it uncomfortable, or is reluctant and not interested to communicate with anaesthetist to gain information. They may believe that they do not have adequate knowledge on the subject to question the anaesthetist or they may believe anaesthetists are professionals and they do whatever beneficial to patients. Therefore taking into account the above factors, the study can be expanded to several directions in order to find out the most familiar source of pre-anaesthetic information for patients and guardians as well as the reasons behind why patients wish or refuse to gain information from those sources.

Delivery of pre-anaesthetic information should be expanded on the areas where patients are more interested in. There should be a proper delivery of pre-anaesthetic information irrespective of type of surgery and type of anaesthesia and efforts should be directed at improving reciprocal communication.

\section{References}

1. White SM. Consent for anaesthesia. J Med Ethics 2004; 30:286-290.

2. Danbury C. General principles of consent. Anaesthesia 2003; 58:281

3. Consent for anaesthesia, Revised edition 2006. The Association of Anaesthetists of Great Britain and Ireland.

4. Cyna AM, Andrew MI, Tan SGM. Communication skills for the anaesthetist. Anaesthesia 2009; 64:658-665.
5. Harms C, Young JR, Amsler F, Zettler C, Scheidegger D, Kindler CH. Improving anaesthetists' communication skills. Anaesthesia 2004; 59:166-172

6. Jlala HA, French JL, Foxall GL, Hardman JG, Bedforth NM. Effect of preoperative multimedia information on perioperative anxiety in patients undergoing procedures under regional anaesthesia. Br J Anaesth. 2010 Mar;104(3):369-74. Epub 2010 Feb 1.

7. Kain ZN, Wang SM, Caramico LA, Hofstadter M, Mayes LC. Parental desire for perioperative information and informed consent: a two-phase study. Anesth Analg. 1997 Feb; 84(2):299-306

8. Thomas GM. McHugh GA. Lack JA. What information do anaesthetists provide for patients? Br J Anaesth 2002; 89:917-9

9. Crawford-Sykes A.M., Hamblento I.R. West Indian Med J, 2001 June : 50 (2) : 159-63.

10. Lonsdale M, Hutchison GL. Anaesthesia. 1991 May;46(5):410-2

11. Barneschi MG, Miccinesi G, Paci E, Novelli GP. Minerva Anestesiol. 1998 Jan- Feb;64(1-2):5-11

12. Farnill D, Inglis S. Anaesthesia. 1994 Feb;49(2):162-4.

13. Oldman M. Moore D. Collins S. "Drug patient information leaflets in anaesthesia: effect on anxiety and patient satisfaction". BJA 92 (6) :854-8 (2004) 